\title{
Performed Lesion Description X Dimension
}

National Cancer Institute

\section{Source}

National Cancer Institute. Performed Lesion Description X Dimension. NCI Thesaurus.

Code C94267.

The measurement of a lesion or location in the ' $X$ ' (first or length) dimension. 